\title{
A "RAÇA" VISTA POR UMA "NEGRA NÃO-AMERICANA": UMA ANÁLISE DO ROMANCE AMERICANAH DE CHIMAMANDA NGOZI ADICHIE
}

\author{
Lara da Rocha Callegari ${ }^{1}$ \\ Universidade de Coimbra \\ (laracallegarii@gmail.com)
}

\begin{abstract}
Resumo: $O$ problema das identidades vem sendo peça central de análises de diversas áreas do saber, dentre elas os estudos sociais e a literatura. No sentido de contribuir para uma justiça cognitiva e social, torna-se indispensável que tais análises sejam feitas de perspectivas pluralizadas para que identidades subalternizadas desafiem as relações de poder estruturais e ganhem voz e vez no meio social, acadêmico e literário. Para tanto, a presente pesquisa apresenta uma análise do romance Americanah (2014) da autora nigeriana Chimamanda Ngozi Adichie, focada no modo de construção ficcional da identidade de raça, em especial das mulheres negras africanas. O romance de Adichie surge como uma alternativa a visão do Norte imperialista eurocentrado que constrói uma visão limitada do Outro. A narrativa da autora nigeriana emancipa e dá voz a uma pluralidade de identidades que comprovam que as identidades não podem ser analisadas a partir de uma perspectiva homogeneizada e (re)constrói o imaginário engessado das mulheres negras africanas diaspóricas como mulheres que narram suas próprias histórias e conquistam autonomia no privado e no público.
\end{abstract}

Palavras-chave: Identidade; Raça; Interseccionalidade; Chimamanda Adichie; Literatura nigeriana.

Abstract: The identity issue has been central in different areas of knowledge, including social studies and literature. In the sense of contributing for social and cognitive justice, it is indispensable that the analysis of this subject matter from pluralized perspectives, so that the subaltern identities can challenge structural power relations and gain a voice and their own turn in the social, academic and literary environments. Therefore, this research presents an analysis of the novel Americanah (2014) by the Nigerian author Chimamanda Ngozi Adichie, focussed on the fictional modes of construction of the identity of race particularly of Black African women. Adichie's novel emerges as an alternative to the view of the imperialist, Eurocentric North wich builds a limited representation of the Other. The narrative of the Nigerian author frees and gives voice to a plurality of identities that prove that they cannot be analyzed through a homogenized perspective, and (re)builds the limited representation of diasporic African black women as women who tell their own stories and conquer autonomy in the private and public spaces

Keywords: Identity; Race; Intersectionality; Chimamanda Adichie; Nigerian Literature.

Resumen: El problema de las identidades viene siendo pieza central de análisis de diversas áreas del saber, entre ellas los estudios sociales y la literatura. En el sentido de contribuir a una justicia cognitiva y social, es indispensable que tales análisis sean hechos de perspectivas pluralizadas para que las identidades subalternizadas desafíen las relaciones de poder estructurales y ganen voz y vez en el medio social, académico y literario. Para ello, la presente investigación presenta un análisis de la novela Americanah (2014) de la autora nigeriana Chimamanda Ngozi Adichie, enfocada en el modo de construcción ficcional de la identidad de raza, en especial de las mujeres negras africanas. La

${ }^{1}$ Mestre em Estudos de Cultura, Literatura e Linguas Modernas pela Universidade de Coimbra. 


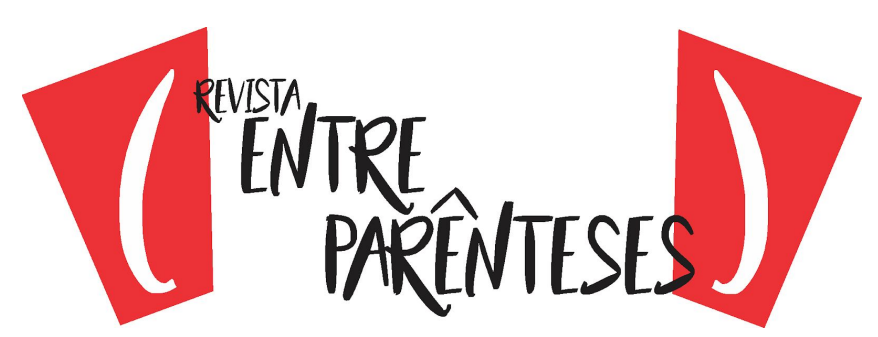

novela de Adichie surge como una alternativa a la visión del Norte imperialista eurocentrado que contradice una visión limitada del Otro. La narrativa de la autora nigeriana emancipa y da voz a una pluralidad de identidades que comprueban que las identidades no pueden ser analizadas desde una perspectiva homogeneizada y re-construye el imaginario enyesado de las mujeres negras africanas días como mujeres que narran sus propias historias y, conquista autonomía en el privado y en el público.

Palabras clave: Identidad; Raza. interseccionalidad; Chimamanda Adichie; Literatura nigeriana.

O presente artigo $^{2}$ nasce da necessidade de cruzar as barreiras literárias que perpetuam cânones eurocentrados e que apresentam as identidades subalternizadas apenas a partir da visão limitada do opressor, reforçando estereótipos que asseguram que o Outro permaneça a margem.

A escolha do romance Americanah (2014), de Chimamanda Ngozi Adichie, escritora nigeriana, foi tomada na consciência da importância de trabalhar narrativas que, mesmo que venham de uma zona crescente no mercado literário global, ainda encontram pouco espaço na academia ou até mesmo nas prateleiras de livrarias. A globalização proporciona cada vez mais a circulação internacional das literaturas marginais, mas esse processo, ao mesmo tempo que une o mundo pelos meios de comunicação em massa, dita regras e estruturas universais (ocidentais) que segregam as comunidades que não fazem parte dessa hegemonia americo-eurocentrada. Para tanto, é necessário trazer narrativas que contem como identidades de raça, vivenciada fora de uma perspectiva ocidentalizada, hegemonicamente branca.

Dois conceitos essenciais para análise do romance Americanah (2014) são a raça e o racismo, pois são tema central da narrativa. Como embasamento teórico desses conceitos, utilizo, entre outros, a reflexão contemporânea do filósofo camaronês Achille Mbembe (2014), em A crítica da razão negra, que afirma que é necessário pensar a raça como um aparato de dominação de uma parcela da

\footnotetext{
${ }^{2}$ Este texto é parte da dissertação de mestrado da mesma autora do artigo, defendido em fevereiro de 2018 na Faculdade de Letras da Universidade de Coimbra, PT.
} 


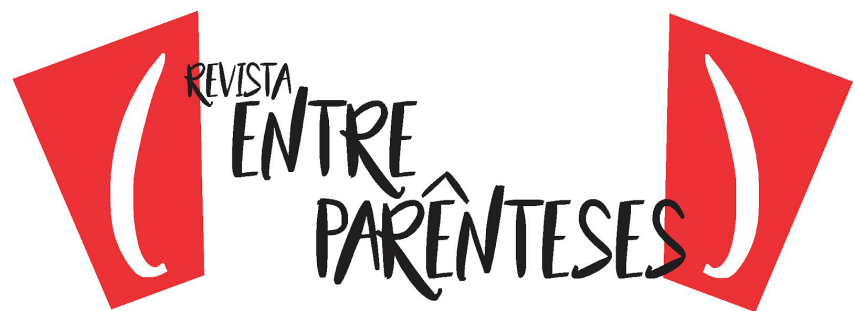

população sobre a outra, através do racismo, mas que esse conceito não é concreto e é alterado pelas práticas que o definem.

O que a teoria de Mbembe (2014) defende, bem como os demais autores que utilizo para abordar o tema, como Paul Gilroy em "It Ain't where you're from, it's where you're At... The dialectics of diasporic identification" (1991), Frantz Fanon em Peles Negras Máscaras Brancas (1983), David Theo Goldberg (2000), em seu artigo "Racial Knowledge", entre outros, é que o conceito de raça não pode ser pensado de forma essencialista, mas sim como um construto social ao serviço dos mecanismos de dominação e regulação dos corpos. Porém, também é utilizado como aparato de resistência por aqueles a quem o próprio conceito nega a existência enquanto sujeitos. Esse conceito é flutuante e alterado pelo contexto social-cultural e econômico. Tendo em vista essa perspectiva de raça atrelada a uma espacialidade e uma temporalidade, pretendo demonstrar no romance de Adichie (2014a) que não deixa nas entrelinhas e sim traz a uma sinuosa superfície a forma distinta como a raça é percebida por dois polos diferentes de sujeitos que partilham essa mesma identidade - os afro-americanos e os negros africanos - e os conflitos que essas perspectivas diferentes acabam gerando.

Em A Crítica da Razão Negra, Achille Mbembe (2014, p. 64) defende que não é suficiente afirmar que raça não tem nada de inato ou essência que a comprove, mas sim que é preciso ressaltar seu papel enquanto um mecanismo de dominação no âmbito de relações de poder e seu conceito não fixo ou estável: ““[...] o adorno móvel de um processo de poder eterno, de incessantes transações que a modificam, substituem, fazendo vacilar o seu conteúdo; ou, ainda, que, não tendo entranhas, uma vez que não têm interior, a raça consiste simplesmente nas práticas que a constituem enquanto tal'”' (MBEMBE, 2014, p. 65). É preciso, pois, entender como funcionam as práticas que continuam a materializar a raça como mecanismo de dominação e a configurá-la como identidade que confina.

Para Mbembe (2014, p. 66), a raça e/ou o racismo providenciam máscaras (cf. Fanon), cobrem verdadeiros rostos humanos para colocar em seu 


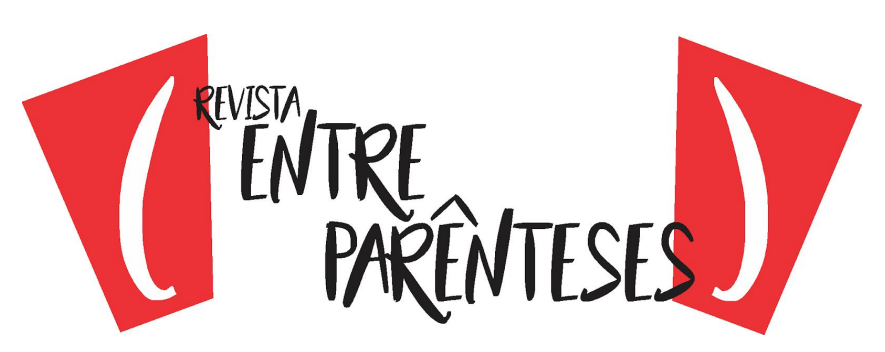

lugar um imaginário, uma construção não real desse rosto para substituir o rosto humano que ali estava. Esse rosto fantasia é colocado para legitimar o negro enquanto não-humano e justificar as atrocidades do racismo (Mbembe, 2014, p. 67).

A construção do Outro é feita a partir da exclusão, a não pertença o define a partir da diferença instituída pelo dominador. No que concerne a raça, a definição do negro é criada a partir do branco: “"For not only must the black man be black; he must be black in relation to the white man"” (FANON, 1983, p. 257).

Fanon, em Peles Negras, Máscaras Brancas (1983, p. 257), aponta que um negro, antes mesmo de ser homem, é um homem negro, sua raça o define antes mesmo de sua chegada e, com ela, os seus estereótipos: “"The evidence was there, unalterable. My blackness was there, dark and unarguable. And it tormented me, pursued me, disturbed me, angered me. Negroes are savages, brutes, illiterates"' (Fanon, 1983, p. 261). A raça aprisiona os indivíduos em um mesmo lote, nega sua individualidade e subjetividade, o ser negro é o que os define e, para tanto, as atitudes de um negro carregam o peso de um conjunto de sujeitos, os acertos são de um negro em específico, os erros pertencem à raça e fecham as portas para qualquer outro que pudesse vir a segui-lo: "“It was always the Negro teacher, the Negro doctor; brittle as I was becoming, I shivered at the slightest pretext. I knew, for instance, that if the physician made a mistake it would be the end of him and of all those who came after him."” (FANON, 1983, p. 261).

A imposição da raça não é um processo pacífico ou passivo, Mbembe (2014, p. 67) atribui a separação entre a essência e a silhueta desses sujeitos bem como a incorporação dessa vivência separada e não-real, a infelicidade do sujeito em performar o que não reflete seu "ser": “"A cena racial é um processo de estigmatização sistemática"”' (MBEMBE, 2014, p. 67).

A invocação da raça pelo oprimido é a representação de um desejo de pertença, uma busca pela origem no passado para traçar o futuro, de trazer sua história para a mão de quem a vive, um desejo de comunidade (Mbembe, 2014, p. 


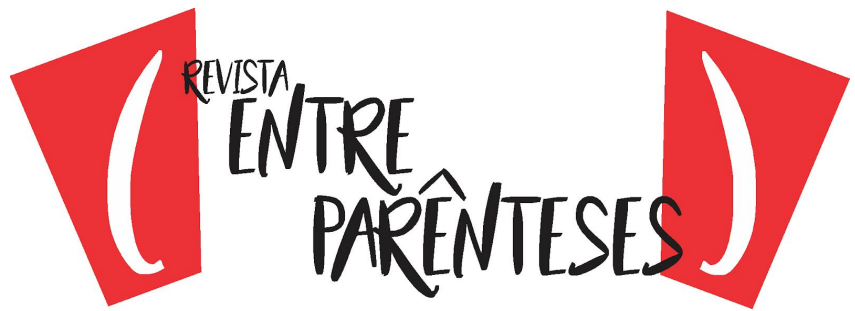

67). O clamor pela raça, segundo o autor, parte de um sentimento de perda, do vazio daquilo que foi arrancado através de um processo de escravatura.

A invocação da raça pode ser lida enquanto resistência, mas também pode surgir como proteção, "'instinto de sobrevivência e de preservação"' (Mbembe, 2014, p. 68). A comunidade racial, a partir dessa visão, é o local de proteção/preservação. Seja na linha de frente ou nas trincheiras, a comunidade racial é a comunidade que devolve o sentimento de pertença que fora tomado dos negros, a comunidade dos que foram invisibilizados, deturpados, a quem foi negada a terra de origem, mas também a própria condição de humanos, dos que foram aprisionados nas máscaras brancas e de ferro. (MBEMBE, 2014, p. 69).

Apesar de não real, ou seja, não biológica, a raça existe, ainda que não destas formas. A construção de um ideal de raça enquanto controle/dominação continua a espalhar efeitos de mutilação de forma perversa e manchada de sangue (MBEMBE, 2014, p. 70).

Adichie, em seu romance Americanah, vencedor do 2013 National Book Critics Circle Award for Fiction, do The Chicago Tribune 2013 Heartland Prize for Fiction, e um dos The New York Times's Ten Best Books of the Year, entre outras distinções, tem como fio condutor a história de um amor, que perdura da adolescência a idade adulta, entre Ifemelu e Obinze, uma história cheia de percalços que tem como eixo a experiência da migração.

O título do livro é uma referência à expressão nigeriana criada para definir aqueles que migram da Nigéria para os Estados Unidos e são de certa forma afetados por essa cultura, seja através de costumes ou sotaque, o que ocorre muitas vezes forçosamente numa tentativa de pertença e identificação com a cultura idealizada da América. O termo "Americanah" aponta para o olhar crítico que a protagonista do romance lança sobre a "americanização" que os imigrantes buscam absorver em uma tentativa de pertencer à cultura americana ou como afirma Martins (2016a), numa tentativa de "desracialização". 


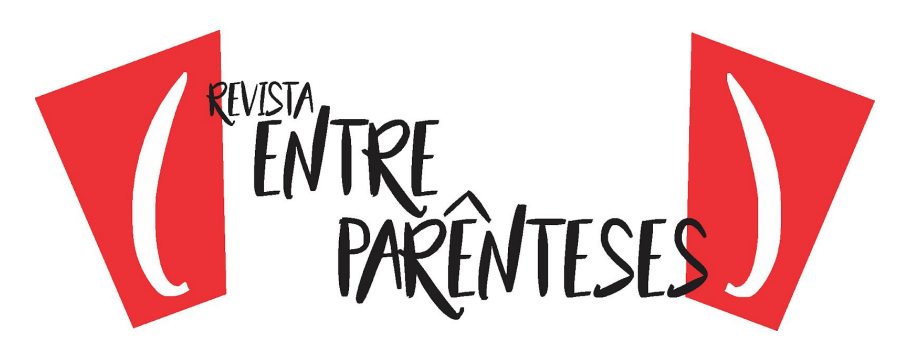

A protagonista, ainda que inserida na cultura americana, não forma sua identidade como imitação do Outro. Ifemelu é configurada como um sujeito híbrido que se forma na diáspora ou até em diferentes diásporas cruzadas, que não busca maquiar sua identidade para transformar-se nesse outro, mas vivencia essa transformação de maneira questionadora e reflexiva, o que a coloca em uma posição emancipadora.

A narrativa é contada de forma não linear, por um narrador heterodiegético omnisciente, que adopta predominantemente uma focalização interna, assumindo o ponto de vista da protagonista. O romance apresenta uma estrutura em três grandes sequências que se podem distinguir pelos respetivos espaços/tempos: Adichie aloca seus personagens em uma Nigéria pós-colonial (na primeira e última sequência) e aborda a diáspora da juventude nigeriana, devido aos conflitos políticos do país, para os Estados Unidos (Ifemelu) e Inglaterra (Obinze), na parte intermédia. Esta estrutura corresponde a momentos de transformação de identidade, através do fenômeno do deslocamento migratório, para ambas as personagens, mas sobretudo para Ifemelu, o alter ego da autora. As memórias da protagonista são trazidas à tona enquanto a mesma está em um salão de cabeleireiro de imigrantes africanas num subúrbio de Boston, num ponto axial da diegese, em que prepara o regresso à Nigéria natal. Da estrutura do romance fazem parte ainda as anotações da protagonista no seu blog, as quais são inseridas como uma espécie de comentário crítico ao plano da narrativa.

Ifemelu é uma jovem urbana, de classe-média, estudante universitária que sai da Nigéria durante o conflituoso período político vivido pelo país devido a um regime governado por militares, e vai para os Estados Unidos em busca de qualidade nos estudos e na vida. É uma personagem de marcada personalidade, muito inteligente, com um espírito profundamente observador e crítico, que não hesita em expressar verbalmente ideias que dificilmente se conformam ao lugar social que deveria ocupar convencionalmente (jovem, mulher, nigeriana). 


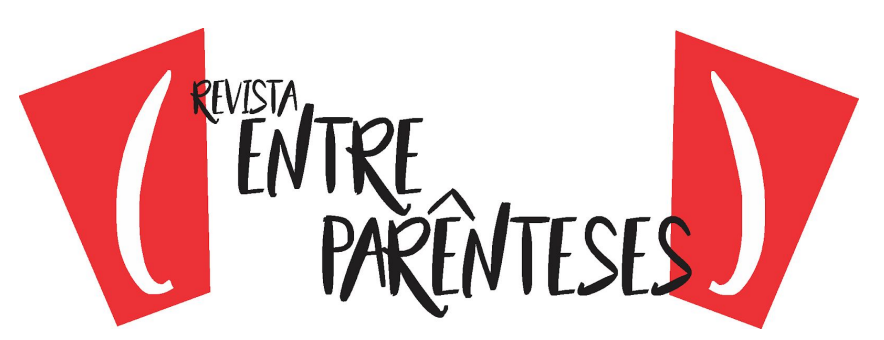

A chegada de Ifemelu na América é apresentada ao leitor depois de 9 capítulos que relatam a juventude na Nigéria e as peripécias do salão de cabeleireiro onde a protagonista recorda aqueles eventos. Também o percurso nos EUA, que culmina no momento em que, cuidando do cabelo, Ifemelu realiza como que um ritual de preparação do retorno à terra natal, surge sob a forma de flash back.

A primeira memória de Ifemelu remete ao perigo de uma história única qu Adichie alerta numa das suas mais conhecidas intervenções públicas, a conferência The Danger of The Single Story, Adichie fala sobre o perigo de uma história única que pode ser (re)contada de formas diferentes, mas se torna absoluta e incontestável. Adichie considera que essa história repetida até se tornar verdade está a serviço das relações de poder:

It is impossible to talk about the single story without talking about power. There is a word, an Igbo word, that I think about whenever I think about the power structures of the world, and it is "nkali." It's a noun that loosely translates to "to be greater than another." Like our economic and political worlds, stories too are defined by the principle of nkali. How they are told, who tells them, when they're told, how many stories are told, are really dependent on power (Brockes, 2017).

A experiência de Ifemelu enquanto imigrante tem início após sua primeira noite no novo lugar. Sua tia decide que a jovem precisa trabalhar para poder sustentar-se em Philadelphia mais tarde e com o visto de estudante consegue apenas trabalhos de extremo baixo rendimento, enquanto utilizar um falso visto pode proporcionar um pagamento maior. Aunty Uju entrega a Ifemelu a carteirinha de Ngozi Okonkwo, uma nigeriana que havia conseguido o visto e passava um período em seu país natal e que, enquanto isso, Ifemelu poderia ocupar seu papel.

A protagonista contesta sua tia, pois a mulher da foto era no mínimo dez anos mais velha que Ifemelu e não apresentava semelhanças para que pudesse passar por ela. Aunty Uju, que já vivia há mais tempo nos Estados Unidos e conhecia os mecanismos as relações de poder que envolvem a raça, alerta a sobrinha: "“We all look alike to white people”" (ADICHIE, 2014a, p. 148). 


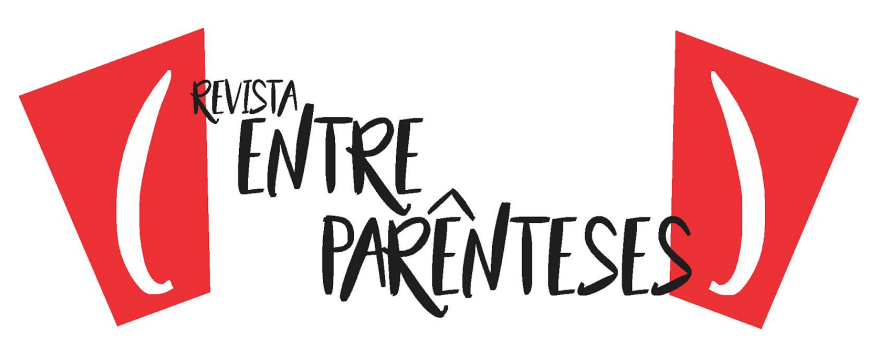

O estereótipo generalizador que é aplicado sobre a raça de Ifemelu e é intensificado pelo conceito homogêneo que é imposto sobre o continente Africano, que na América é propagado como algo unificado e com sujeitos que partilham de uma identidade una, é confirmado por Ginika, a melhor amiga de infância de Ifemelu que a recebeu em Philadelphia. Ifemelu vai em busca de trabalho e acaba por confundir o seu nome verdadeiro com o nome dos papéis falsos. Ao relatar a situação para a amiga mais experiente na realidade dos EUA, Ifemelu é confrontada não somente com a forma como os americanos possuem uma "história única" relativamente aos imigrantes africanos e a África, como com a forma como estes imigrantes usam esses estereótipos em seu favor, como uma forma de resistência bastante irônica: "Later Ginika said, 'You could have just said Ngozi is your tribal name and Ifemelu is your jungle name and throw in one more as your spiritual name. They'll believe all kinds of shit about Africa'" (ADICHIE, 2014a, p. 160). Surge, mais uma vez, a sensação de estranheza e não pertencimento que a recente imigrante experimenta.

O espaço está atrelado a contextos socioculturais, políticos e históricos, para tanto é preciso levar em consideração que as identidades não funcionam da mesma forma em espaços diferentes. A personagem Ifemelu, ao sair de seu país natal, a Nigéria e, deslocar-se para os EUA descobre ainda a sua identidade racial que, do local de partida da personagem, não carregava uma influência relevante.

Ifemelu não tarda a perceber as divisões espaciais que a identidade de raça, por ela recém descoberta, configura, de forma conjunta com hierarquias de classe, pois a própria criação do conceito de raça só se tornou possível a partir de um sistema capitalista que visava manter as relações de poder na mão de uma raça, a branca e, para isso, subjuga a outra, a raça negra:

During her first year in America, when she took a New Jersey Transit to Penn Station and then the subway to visit Aunty Uju in Fitlands, she was struck by how mostly slim white people got off at the stops in Manhattan and, as the train went further into Brooklyn, the people left were mostly black and fat (Adichie, 2014a, p. 06). 


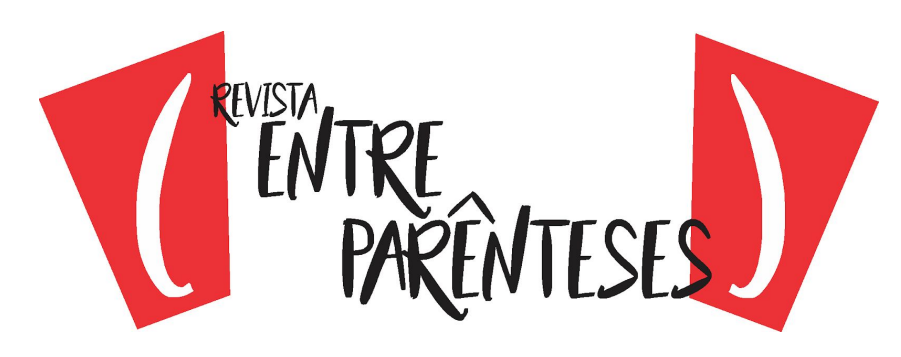

A viagem de Ifemelu até Brooklyn e a constatação da segregação racial é reflexo da interseccionalidade entre raça e classe que culminam em uma população negra e economicamente desfavorecida devido a um racismo estrutural que empurra a população Afro-Americana para a margem.

Ifemelu acaba encontrando emprego de babá, emprego recorrente a imigrantes, na casa de uma família branca com um alto poder aquisitivo com um patrão pouco presente, Don, uma patroa doce e sensível, Kimberly, e duas crianças, Taylor, um menino e Morgan, uma menina um tanto quanto revoltada. Logo na primeira entrevista, na qual Ifemelu não consegue o emprego que mais tarde é chamada, a protagonista é apresentada a Laura, irmã de Kimberly.

Laura compara sua colega Africana que ela supõe ser de Uganda com o médico que conheceu e concomitantemente com outras mulheres afro-americanas: "'I knew a woman from Africa who was just like this doctor, I think she was from Uganda. She was wonderful, and she didn't get along with the African-American woman in our class at all. She didn't have all those issues"' (ADICHIE, 2014a, p. 207). Para Laura e a sua perspetiva colonial e racista, a raça é o determinante da situação, e a ausência de "race issues" em uma imigrante africana negra em contraponto a uma afro-americana é digna de elogios, pois a personagem branca não considera o passado escravocrata que se faz presente durante toda a vida para negra americana, enquanto a imigrante não vivenciou tal realidade.

Ifemelu decide elucidar para a irmã da patroa a diferença da identidade de raça atrelada a sujeitos com vivências e provenientes de espaços diferentes: "Maybe when the African American father was not allowed to vote because he was black, the Ugandan's father was running for parliament or studying at Oxford', Ifemelu said" (ADICHIE, 2014a, p. 207). Os contextos social-político-históricos desses dois sujeitos não correspondem, a identidade de raça para uma afro-americana, que nasceu e cresceu inserida em uma sociedade racializada e preconceituosa, não terá mesma leitura para uma que provém de um espaço em que 


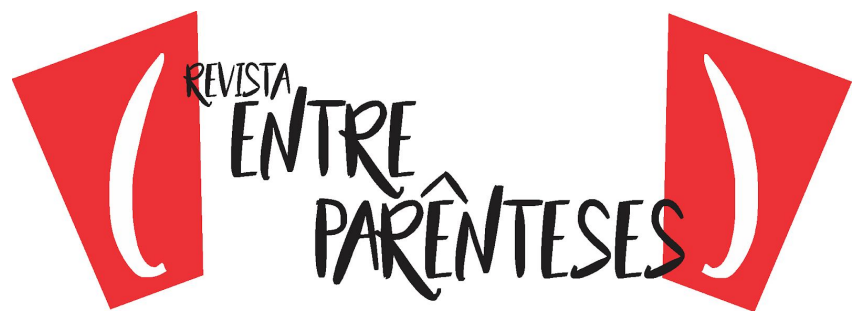

raça, depois da independência do colonialismo, deixou de ser fator determinante ou segregador.

A língua é viva e funciona como aparato de dominação e, também de resistência. As palavras que servem para aprisionar minorias em estereótipos e que são denunciadas por Ifemelu são recorrentes nos discursos carregados de racismo, seja ele velado ou não. Uma das palavras mascaradas utilizada pela então patroa de Ifemelu e que pode soar como elogio é a palavra 'beautiful'. O significante produz significados preconceituosos e generalizadores, Kimberly quer proteger-se do rótulo de racista e acaba performando, de forma nada sutil, um discurso racista, discurso esse que não passa despercebido a Ifemelu:

Ifemelu would come to realize later that Kimberly used "beautiful" in a peculiar way. "I'm meeting my beautiful friend from graduate school." Kimberly would say or "We're working with this beautiful woman on the inner-city project", and always, the women she referred to would turn out to be quite ordinary-looking, but always black (Adichie, 2014a, p. 180).

A insistência de Kimberly em elogiar a beleza de uma mulher negra, seja ela qual for, é uma forma de apagar a individualidade de cada uma, como se todas as mulheres negras fossem igualmente belas e a cor delas não fosse percebida pela chefe de Ifemelu, ao que denomina-se "color blind", enquanto performam discursos e práticas que vão de encontro a essa postura "desracializada". Referir-se a mulheres negras como belas apenas por serem negras é uma tentativa falha de mascarar o preconceito e acaba por provar ser uma forma legítima de discriminação: [...] "'Isn't she just stunning?' 'No, she isn't' Ifemelu said 'You know you can just say «black». Not every black person is beautiful"' (ADICHIE, 2014a, p. 181).

A protagonista acaba por relacionar-se com o primo de Kimberly de Maryland, Curt, um jovem branco, atraente e rico. O relacionamento dos dois inicia-se como um conto de fadas, Curt é alegre e agradável o tempo todo, Ifemelu começa a gostar do jovem por ele gostar tanto dela. 


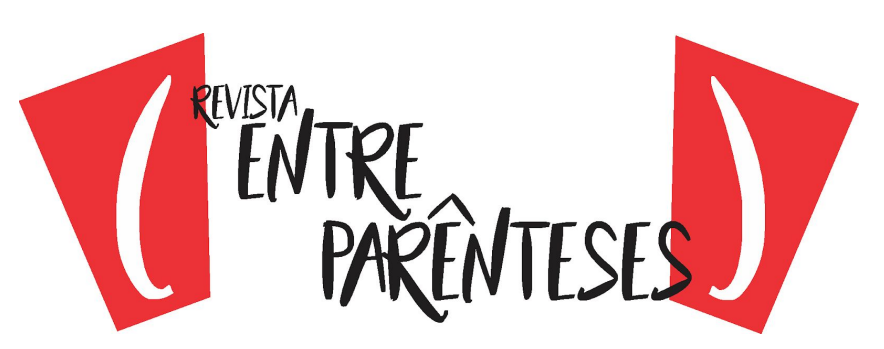

Curt consegue um emprego para Ifemelu e, com o emprego, a possibilidade de um green-card. O novo emprego traz à tona um novo questionamento, o cabelo de Ifemelu. A protagonista é alertada para tirar as tranças do cabelo e alisá-lo, pois, esse poderia ser um fator determinante para a contratação de Ifemelu, ainda que não explicitamente. O relacionamento inter-racial de Ifemelu e Curt gera leituras diferentes da situação. Curt não aceita que Ifemelu tenha que mudar para conseguir o emprego e não consegue enxergar como uma sociedade racista interfere nos mais diversos aspectos das mulheres negras, enquanto para Ifemelu e para as mulheres negras que a aconselharam essa percepção é clara, o cabelo de uma mulher negra é político e pode fechar portas quando não adaptado a uma estética branca.

Ainda que Curt fosse, para um homem branco e rico, o mais compreensivo possível, seus privilégios interferiam no seu julgamento no que tange a questões raciais. Em uma discussão sobre uma revista de beleza exclusiva para mulheres negras que, para o namorado de Ifemelu, era racialmente distorcida por protagonizar apenas uma raça, a negra, a protagonista decide levar o namorado até uma livraria para provar seu ponto: todas as revistas da loja tinham como maioria absoluta mulheres brancas e, quando não-brancas, racialmente ambíguas podendo pertencer tanto à Índia quanto a Porto Rico, e que, quando negras, tinham pele clara. Nenhuma delas poderia representar mulheres como Ifemelu, negra de pele escura com cabelo afro e, para tanto, as dicas de beleza, mesmo quando propostas a "todas as mulheres", não a incluíam. O espaço da margem, como afirma hooks (2015) permite que quem esteja nela perceba o todo, como é o caso de Ifemelu, mas quem ocupa o centro está centrado em si próprio, mesmo quando pensa incluir o outro, está segregando, como as revistas que se propõem incluir todas as mulheres, sendo que o todas se referem a um padrão restrito:

None of them is dark. Not one of them looks like me, so I can't get clues for makeup from these magazines. Look, this article tells you to pinch your cheeks for color because all their readers are supposed to have cheeks you can pinch for color. This tells you about different hair 


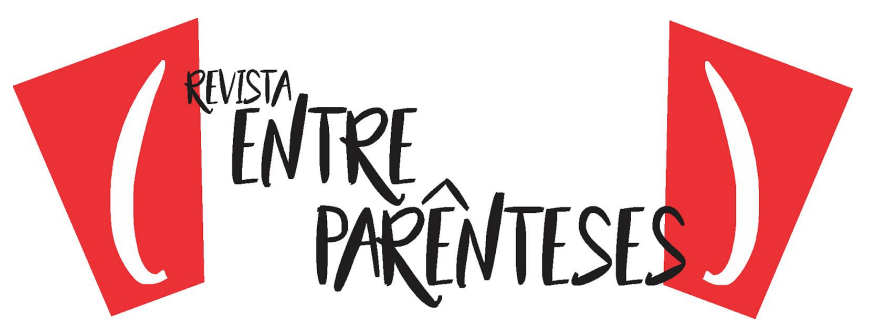

products for everyone - and 'everyone' means blonds, brunettes, and red-heads. I am none of those. And this tells you about the best conditioners - for straight, wavy, and curly. No kinky. See what they mean by curly? My hair could never do that. This tells you about matching eye color and eye shadow - blue, greens, and hazel eyes. But my eyes are black so I can't know what shadows work for me. This says that pink lipstick is universal, but they mean universal if you are white because I would look like a golliwog if I tried that shade of pink (Adichie, 2014a, p. 366).

A percepção da personagem parte de quem experimenta o espaço da margem. Para Curt, sujeito que pertence ao topo da pirâmide social, apenas situações explícitas de preconceito são identificadas, enquanto o silenciamento e a exclusão são perpetuados em estruturas engessadas e negligenciadas que mantém a supremacia de uma raça sobre a outra, os pequenos detalhes configurados como vitimismos ou exageros que mascarados no estereótipo se tornam verdades absolutas e não abrem espaço para serem (des/re) construídos.

Ifemelu cumpre o seu propósito: se essas estruturas permanecem mascaradas, junto com os que a perpetuam, por ela serão expostas e problematizadas, sairão do anonimato confortável que faz com que pessoas brancas identifiquem preconceito e privilégio apenas em situações extremas e performem ou se mantenham em silêncio nas discriminações que permeiam situações do cotidiano.

O relacionamento de Ifemelu com Curt chega ao fim quando a protagonista o trai com o vizinho e conta para o namorado, que pergunta em primeira instância a raça do homem com quem ela o traiu. $\mathrm{O}$ fim do namoro com Curt rendeu alguns posts no blog de Ifemelu, assim como foi o próprio relacionamento que deu início ao projeto da blogueira, ao ser interpelada com questões suscitadas pelo relacionamento inter-racial, em especial entre uma mulher negra imigrante com um homem branco de classe alta (levando em consideração questões de gênero e raça - relacionamentos inter-raciais onde o homem é negro e a mulher é branca não encontram a mesma resistência). 


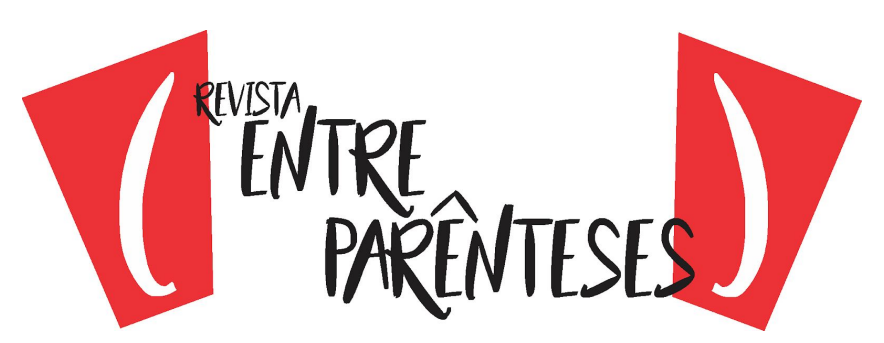

O blog da protagonista chamado "Raceteenth or Various Observations About American Blacks (Those Formerly Known as Negroes) by a Non-American Black", no qual a personagem aborda situações de seu cotidiano e suas percepções sobre a relação da América com a raça negra enquanto negra não-americana. Ifemelu pertence a essa margem que resiste, que (re)configura e desloca fronteiras, um local que descoloniza o pensamento e problematiza estruturas consolidadas por uma hegemonia dos que permanecem no centro. O blog de Ifemelu é o que hooks (2014) defende como o empoderamento do local de fala, de uma visão que parte daquele que de fato vê, não daquele que relata a partir da visão do Outro. Com um discurso irônico e sempre bem-humorado, as indagações e constatações da blogueira perpassam por questões por ela vivenciadas como a representatividade das mulheres negras na indústria da beleza, o colorismo que intensifica as opressões vivenciadas por mulheres negras de pele escura, política e sua relação com a raça, apropriação cultural, privilégio branco e relacionamentos inter-raciais.

Adichie apresenta uma estrutura bipartida nesta parte da narrativa. Ifemelu experimenta relacionamentos que colocam em confronto identidades raciais diferentes, como Curt, mas também apresenta um relacionamento onde a mesma identidade de raça paradoxalmente não aproxima, mas afasta, devido à forma com que essa identidade é construída em contextos sociais diferentes. É o caso de Blaine, o namorado afro-americano de Ifemelu. A autora destaca a construção de dois pólos diferentes entre negros americanos e negros nigerianos que é produzida pelo fator da imigração, no qual o espaço nacional e a pertença (ou não) a um núcleo diaspórico que já faz parte de uma entidade nacional, é um determinante para o distanciamento social.

Foi o blog de Ifemelu que trouxe Blaine para sua vida definitivamente, em uma convenção de blogueiros negros. Ifemelu reconhece o jovem estranho que despertou seu interesse em uma viagem de trem, e ambos se reconhecem e acabam trocando e-mails e telefone após quase dez anos do primeiro encontro. 


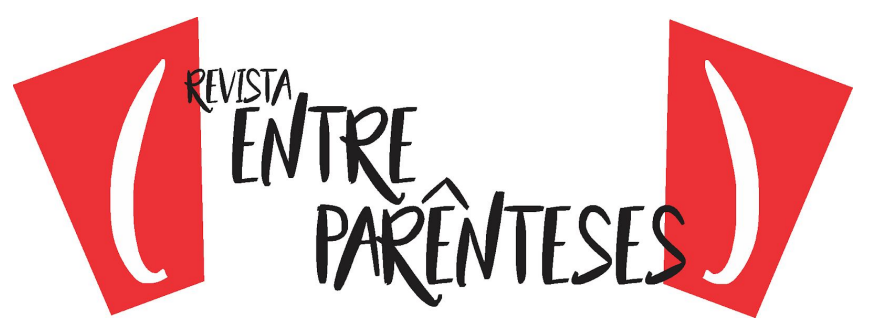

O relacionamento dos dois se aprofunda e Ifemelu se muda para o apartamento de Blaine e de lá escreve seu blog. A problemática da percepção da raça do casal de backgrounds diferentes surge quando Blaine começa a interferir nas publicações de Ifemelu, o namorado da blogueira começa a cobrar uma certa responsabilidade intelectual nos posts, alegando que Ifemelu exerce uma influência sobre os jovens negros leitores do blog:

She had written a post about inner cities - "Why Are the Dankest, Drabbest Parts of American Cities Full of American Blacks?" - and he told her to include details about government policy and redistricting. She did, but after reading it, she took down the post. "I don't want to explain, I want to observe," she said.

"Remember people are not reading you as entertainment, they're reading you as cultural commentary. That's a real responsibility. There are kids writing college essays about your blog," he said.(Adichie, 2014a, p. 386).

O conflito entre o casal é decorrente da forma com que ambos experimentam a questão racial, Blaine está inserido em uma cultura com um passado escravocrata que oprime e segrega os negros, enquanto Ifemelu só sente a raça como uma marca identitária de diferença ao ser inserida no contexto americano e por isso se considera uma observadora e não uma militante de uma causa, pois sua vivência original na Nigéria não corresponde a essa estrutura social racializada.

As situações em que as percepções do casal sobre raça divergem são frequentes ao longo da narrativa. As linhas ficcionais de Adichie tematizam esse distanciamento que o contexto histórico-cultural causa, refutando a ideia limitadora de que raça é um fator biológico ou essencialista, e mostrando-a como um construto cultural e social a serviço de relações de poder que imperam em determinados espaços, como nos Estados Unidos.

Blaine apresenta sua irmã para Ifemelu. Shan é uma escritora e, durante uma conversa, revela ter um amigo escritor Nigeriano que lê o blog de Ifemelu e ficaria surpreso em descobrir que a blogueira é africana. Seu palpite seria caribenha, 


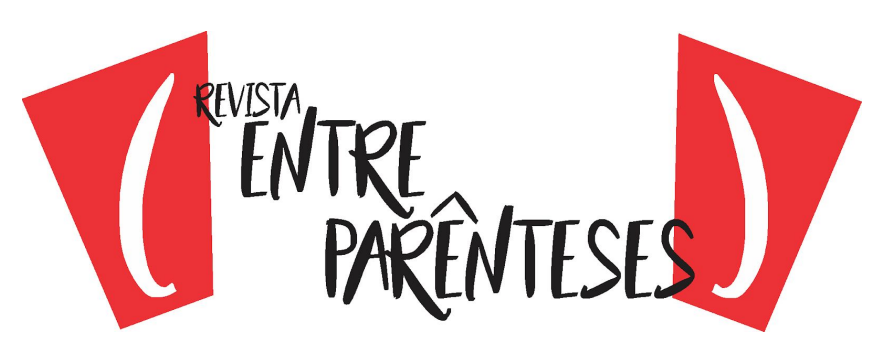

uma vez que os africanos não se preocupariam com questões raciais. Mais uma vez, a narrativa traz à superfície a diferença da percepção de raça devido ao espaço que os sujeitos se alocam, pois para Ifemelu a raça se tornou um assunto a ser considerado no momento em que essa identidade se tornou parte de sua vivência, ainda que da perspectiva de uma imigrante.

O blog de Ifemelu se torna assunto na roda de amigos de Blaine quando Shan traz à tona a problemática que circunda a literatura na América quando a raça é a temática. A irmã de Blaine afirma que não existe espaço para que romances sejam escritos de forma honesta sobre raça e a maneira que as pessoas são afetadas por ela e Grace, amiga de Blaine, complementa: “Or just find a white writer. White writers can be blunt about race and get all activist because their anger isn't threatening' [...]" (ADICHIE, 2014a, p. 417). A colocação de Grace sobre os autores brancos ser permitido falarem de raça, devido à sua posição confortável e de outsiders do assunto, é estendida a Ifemelu e sua condição de imigrante. A raça aqui não é fator integrante, a condição de imigrante coloca Ifemelu à margem de um grupo que, no fundo, se apresenta como o grupo verdadeiramente oprimido e objeto de maior estereotipização na sociedade americana, cego para a marginalização da população negra africana imigrante:

"You know why Ifemelu can write that blog, by the way?" Shan said. "Because she's African. She's writing from the outside. She doesn't really feel all the stuff she's writing about, It's all quaint and curious to her. So she can write it and get all these accoolades and get invited to give talks. If she were African American, she'd just be labeled angry and shunned." (Adichie, 2014a, p. 418).

A afirmação de Shan sobre a diferença de Ifemelu, uma negra não-americana, escrever um blog sobre raça aponta para o imaginário identitário que os afro-americanos constroem em torno da raça. Trata-se de uma comunidade diaspórica, cuja origem remonta à escravatura, e que, apesar de historicamente segregada, encara a sua antiguidade como fazendo parte da nação americana e da 


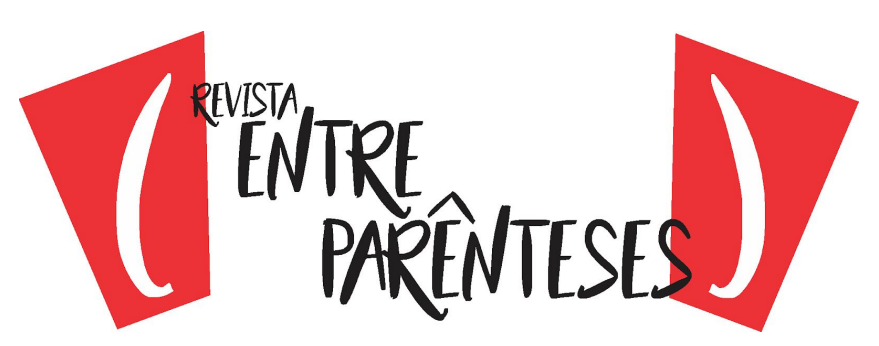

sua memória. Ainda que o imigrante partilhe da mesma cor de pele, a questão da raça não é percebida da mesma maneira, pois o sujeito imigrante é um corpo estranho em uma unidade nacional e na própria diáspora afro-americana.

A cor da pele não é fator definitivo na constituição identitária, a transversalidade de fatores como nacionalidade, origem e classe social alocam sujeitos que partilham a mesma cor da pele em categorias diferentes. Ainda que a cor da pele seja partilhada por ambos, o contexto histórico-cultural faz com que as disparidades das vivências de um/a negro/a americano/a, inserido/a em um espaço com um passado escravocrata que ainda é latente em suas vidas, e de um/a negro/a não-americano/a com um passado colonial também ainda presente, sejam interpelados de forma diferente pela raça. Ou seja, a categoria raça não é dissociável da construção cultural própria de cada comunidade diaspórica, em particular dos signos e narrativas constituintes da memória e evocadores da origem. São estes, por cima da raça, que se tornam fatores de inclusão e de exclusão, mesmo que o fator racial seja exibido como signo identitário agregador.

Da mesma maneira, no contexto histórico dos EUA como país imperialista do Norte construiu-se uma representação de África que se coloca a frente das identidades africanas dos sujeitos que realmente vêm de África e acabam por subjugar, negar a cultura de quem dela provém. O "Africanismo" (termo cunhado por Valentin Mudimbe por associação com o conceito "Orientalismo" de Edward Said relativo às representações ocidentais do Outro) dos afro-americanos acaba, muitas vezes, por resultar na reprodução de estereótipos de originalidade mítica, fantástica e primitiva dos africanos. Ifemelu recebe um alerta de um dos estudantes que fazem parte da African Students Association sobre com quem formar laços e, em seu discurso, fica explícito que raça nem sempre pode ser pensado como fator integrador e que, muitas vezes, o contexto social será determinante para essa divisão:

Try and make friends with our African-American Brothers and sisters in a spirit of true pan-Africanism. But make sure you remain friends 


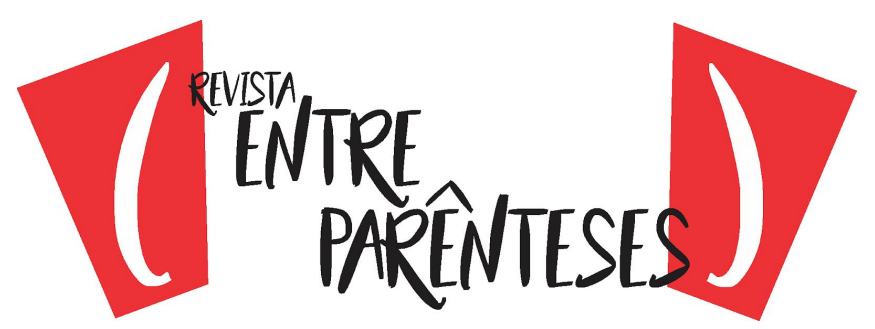

with fellow Africans, as this will help you keep your perspective. Always attend African Students Association meetings, but if you must, you can also try the Black Student Union. Please, note that in general, African Americans go to the Black student Union and Africans go to the African Students Association. Sometimes it overlaps but not a lot. The Africans who go to BSU are those with no confidence who are quickly to tell 'I am originally from Kenya' even though Kenya just pops out the minute they open their mouths. The African Americans who come to our meetings are the ones who write poems about Mother Africa and think every African is a Nubian queen. (Adichie, 2014a, p. 172).

O conceito de diáspora africana foi apropriado pelos afro-americanos que reclamam a africanidade para si e seus antepassados e negam esse direito às gerações diaspóricas contemporâneas. A identidade de imigrante é formadora de laços para os africanos que, assim como os latinos e os indianos, dividem os percalços de ser um estrangeiro nos Estados Unidos e enfrentam os estereótipos a eles associados por uma cultura imperialista e dominante. Ifemelu é alertada sobre a possibilidade de fazer amizades entre os outros imigrantes, com menos ressalvas do que com os afro-americanos:

You will also find that you might make friends more easily with other internationals, Koreans, Indians, Brazilians, whatever, than with Americans both black and white. Many of the internationals understand the trauma of trying to get an American visa and that is a good place to start a friendship (Adichie, 2014a, p. 173).

Muitos dos questionamentos de Ifemelu sobre a identidade de raça e sua consequência nos sujeitos que a experimentam se tornam uma barreira em seu relacionamento com Blaine, especialmente após um fato isolado, uma atitude racista da universidade, que chamou a polícia ao ver dois homens negros entregando dinheiro um ao outro e supôs que seria relacionado ao tráfico de droga, enquanto eram apenas dois amigos pagando uma dívida. Blaine decide organizar um protesto e Ifemelu decide não ir e opta em comparecer a uma festa de despedida de um remoto conhecido. 


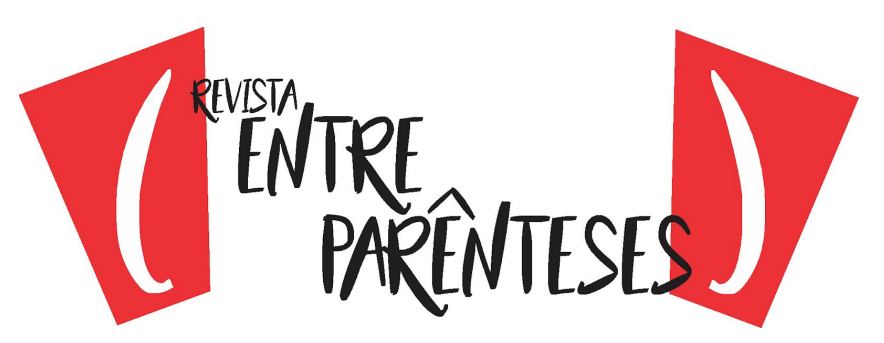

Ao descobrir que Ifemelu mentiu sobre não ter ido ao protesto, Blaine fica profundamente ofendido, mas a ofensa não parece ser devida a uma traição ao relacionamento dos dois, mas a uma causa: “'“You know it's not just about writing a blog, you have to live like you believe it. That blog is a game that you don't really take seriously, it's like choosing an interesting elective evening class to complete your credits'”'" (ADICHIE, 2014a, p. 427-428). Ifemelu deixa claro o tom de acusação, mas não apenas pela falta de comprometimento com a causa, mas uma acusação sobre sua identidade, sobre sua Africanidade ou, como me refiro acima, sobre a negação da "verdadeira" identidade negra, na perspetiva dos afro-americanos, àqueles que, apesar de negros e africanos, ou justamente por causa disso, não pertencem à comunidade negra norte-americana: "She recognized, in his tone, a bubtle accusation, not merely about her laziness, her lack of zeal and conviction, but also about her Africanness; she was not sufficiently furious because she was African, not African-American" (ADICHIE, 2014a, p. 428).

Após nove dias sem se falar, o relacionamento aos poucos é retomado, mas Ifemelu não sentia mais a mesma atração por Blaine. O que os unia era uma causa em comum, Barack Obama, a eleição presidencial e a probabilidade de um futuro presidente negro nos Estados Unidos da América.

Em uma discussão sobre o racismo entre Ifemelu e negros e negras afro-americanos e de diferentes países africanos, no período das eleições em que o primeiro presidente negro nos Estados Unidos se tornava uma real possibilidade e proporcionava acaloradas conversas sobre o tema, Ifemelu traz como argumento a experiência adquirida no relacionamento inter-racial com Curt:

"[...] The only reason you say race was not an issue is because you wish it was not. We all wish it was not. But it's a lie. I came from a country where race was not an issue; I did not think of myself as black and I only became black when I came to America. When you are black in America and you fall in love with a white person, race doesn't matter when you're alone together because it's just you and your love. But the minute you step outside, race matters. But we don't talk about it. We don't even tell our white partners the small things that 


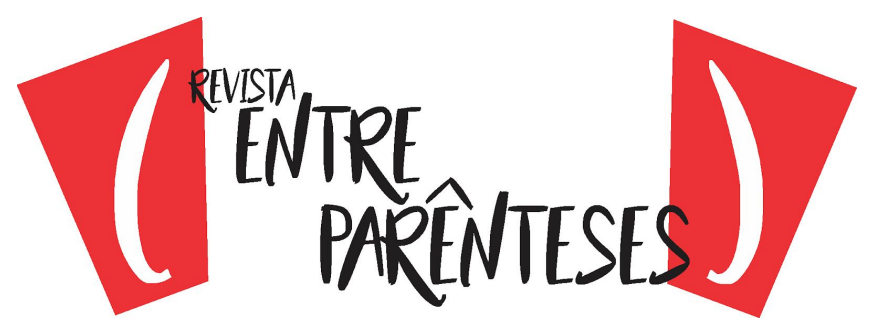

piss us off and the things we wish they understood better, because we're overreacting, or we're being too sensitive. And we don't want them to say, look how far we've come, just forty years ago it would have been illegal for us to even be a couple blah blah blah, because you know what we're thinking when they say that? We're thinking why the fuck should it ever been illegal anyway? [...]" (Adichie, 2014a, p. 359-360).

A blogueira afirma que negar a raça como um problema no relacionamento é inútil, pois ela está lá e sempre será companhia, seja em público com os olhares desaprovadores, ou na opção por não revelar os racismos vivenciados e o quanto eles deixam quem os sofre indignados. Mesmo em um relacionamento amoroso, a raça negra é subjugada, é silenciada em nome de uma relação pacífica ou na tentativa de mascarar a interferência da raça e dos racismos que assombram os relacionamentos amorosos entre brancos e negros, é trazer para o privado uma questão pública, o racismo é estrutural e não pode ser deixado de lado ou coberto com panos quentes, nem em nome do amor.

O romance de Adichie proporciona uma visão das relações raciais ampla, que não se limita às relações entre brancos e negros, mas que expande essa perspectiva para relações entre negros em diferentes espaços, que no romance são representados pela Nigéria, Estados Unidos e Inglaterra. Em um dos posts do blog a personagem descreve como a raça funciona na América:

So lots of folk - mostly non-black - say Obama's not black, he's biracial, multiracial, black and white. But race is not biology; race is sociology. Race is not genotype; race is phenotype. Race matters because of racism. And racism is absurd because it's about how you look. Not about the blood you have. It's about the shade of your skin and the shape of your nose and the kinky of your hair (Adichie, 2014a, p. 419).

A afirmativa de Ifemelu sobre o conceito de raça corrobora com o pensamento de Mbembe anteriormente discutido: raça é socialmente construída e está a serviço de relações de poder que se fortalecem através do racismo. Ifemelu 


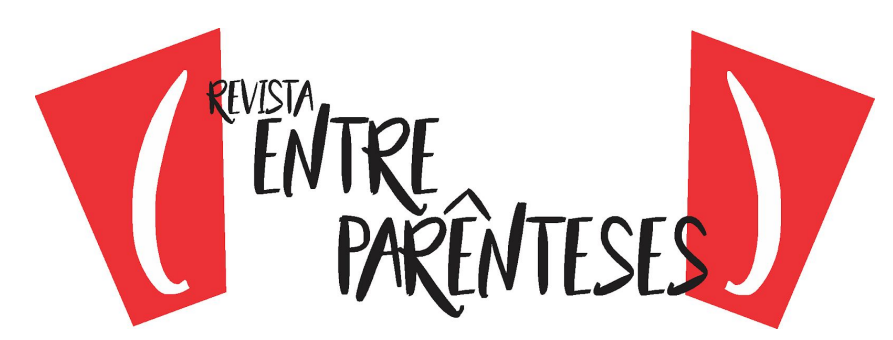

reflete sobre a experiência de muitos imigrantes africanos que são automaticamente categorizados como negros ao chegarem nos EUA, independentemente de pertencerem a diferentes nações com backgrounds diversos, têm suas identidades silenciadas para dar lugar a uma identidade imposta e generalista:

Dear Non-American Black, when you make the choice to come to America, you become black. Stop arguing. Stop saying I'm Jamaican or I'm Ghanaian. America doesn't care. So what if you weren't "black" in your country? You're in America now. We all have our moments of initiation into the Society of Former Negroes. Mine was in a class in undergrad when I was asked to give the black perspective, only I had no idea what that was. So I just made something up [...] So you're black, baby. And here's the deal with becoming black: You must show

that you are offended when such words as "watermelon" or "tar baby" are used in jokes, even if you don't know what the hell is being talked about - and since you are a Non-American Black, the chances are that you won't know [...] When you watch television and hear that a "racist slur" was used, you must immediately become offended. Even though you are thinking "But why won't they tell me exactly what was said?" Even though you would like to be able to decide for yourself how offended to be, or whether to be offended at all, you must nevertheless be very offended [...] Most of all, do not be angry. Black people are not supposed to be angry about racism. Otherwise you get no sympathy. This applies only for white liberals, by the way. Don't even bother telling a white conservative about anything racist that happened to you. Because the conservative will tell you that YOU are the real racist and your mouth will hang open in confusion (Adichie, 2014a, p. 220).

A blogueira denuncia as contradições da imposição de uma identidade racializada e do respectivo padrão de comportamento, a qual adquire matizes diferentes consoante o agente de poder: ao mesmo tempo que, devido à sua cor da pele, uma indignação é esperada dela, também o direito de demonstrar sua raiva perante situações racistas lhe é negado por brancos, liberais ou conservadores. Ainda que a carta do racismo reverso seja jogada apenas pelos conservadores, os liberais também rejeitam a reação não pacífica de um negro que tenha sofrido racismo, admitindo apenas uma posição que suscite compaixão. Já os "former 


\section{("intirer}

negroes", ou seja, os afro-americanos descendentes de escravos, parecem formar um grupo fechado com rituais de resistência institucionalizados e que, mesmo que na margem, já faz parte do corpo nacional dos EUA. Por essa razão, o "non-american black" permanece estrangeiro a esse corpo e regista um momento "iniciático" que é um momento de marcação de diferença, de estranhamento, de incorporação apenas relativa. $O$ imigrante africano permanece numa prateleira à parte da "negritude" norte-americana. Ironicamente, a sua origem africana real desaparece para ser submetida a uma identidade "afro"/negra sedimentada enquanto elemento de ligação e de identificação de uma diáspora de há muitos séculos.

Em um outro post de seu blog, a protagonista faz um apelo aos "não-negros" em relação aos seus posicionamentos sobre racismo. A tentativa de negar situações racistas perpetua a superioridade de uma raça sobre a outra e não reconhece as relações de poder que utilizam de mecanismos racistas para manter a subjugação dos negros pelos brancos. Ifemelu refuta um argumento frequentemente utilizado por aqueles que se encontram no topo da pirâmide racial, a não percepção da cor na tentativa de livrarem-se da posição de racistas. Fanon (1983), como cito anteriormente, alega a impossibilidade de chegar, enquanto negro, em um ambiente e ser lido apenas como homem, pois sua raça chega antes e prediz sua identidade. A partir de suas vivências, Ifemelu denuncia em seu blog a tentativa de negligenciar a raça por aqueles que a utilizam de forma mais perversa e que colhem os privilégios dessa construção social, os brancos:

Dear American Non-Black, if an American Black person is telling you about an experience about being black, please do not eagerly bring up examples from your own life. Don't say "it's just like when I..." You have suffered. Everyone in the world has suffered. You have not suffered precisely because you are an American Black. Don't be quick to find alternative explanations for what happened. Don't say "Oh, it's not really race, It's class. Oh, it's not race, it's gender." Oh it's not race, it's the cookie monster. You see, American Blacks actually don't WANT it to be race. They would rather not have racist shit happen. So maybe when they say something about race, it's maybe 


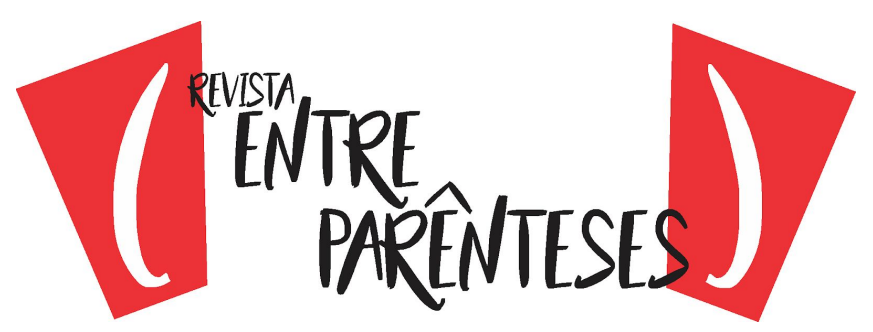

because it actually is? Don't say "I'm color-blind" because if you are color-blind, then you need to see a doctor [...] (Adichie, 2014a, p. 404).

O blog de Ifemelu, assim como o próprio romance Americanah, não temem em apontar as situações racistas em diferentes esferas sociais e nominar quem as infringe e denunciar os privilégios de uma raça sobre a outra:

[...] but racism is about the power of a group and in America it's white folks who have that power. How? Well, white folks don't get treated like shit in upper-class African-American communities and white folks

don't get denied bank loans or mortgages precisely because they are white and black juries don't give white criminals worse sentences than black criminals for the same crime and black police officers don't stop white folk for driving while white and black companies don't choose not to hire somebody because their name sounds white and black teachers don't tell white kids that they're not smart enough to be doctors and black politicians don't try some tricks to reduce the voting power of white folks through gerrymandering and advertising agencies don't say they can't use white models to advertise glamorous products because they are not considered "aspirational" by the main-stream (Adichie, 2014a, p. 405).

Ainda sobre o racismo, a personagem traz à tona a forma velada com que o racismo é tratado e como o discurso é desvinculado da prática, pois o racismo é reconhecido, mas a ele não são atribuídos rostos e vozes, é um crime sem culpados, uma história sem personagens ou com personagens caricatos que se afastam das linhas reais dos meios sociais. Com a ironia já característica da linguagem da blogueira, Ifemelu aponta dedos: os racistas são nossos vizinhos, nossos familiares, somos nós, as atitudes racistas são configuradas também no viés inconsciente, nas mais sutis formas, nas atitudes que não vemos, mas lá estão e se propagam no espaço do silenciamento e de uma providencial cegueira e não cabe aos réus não-confessos julgarem e darem o veredicto, mas sim aos que sentem todas as formas que o racismo, transvestido ou não, apresenta: 


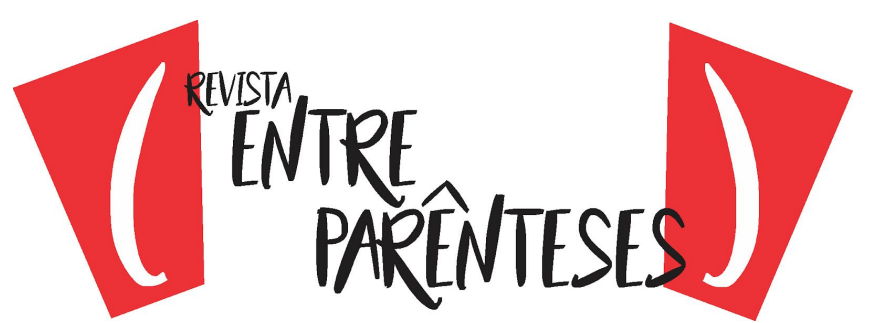

In America, racism exists but racists are all gone. Racists belong to the past. Racists are the thin-lipped men white people in the movies about the civil rights era. Here's the thing: the manifestation of racism has changed but the language has not. So if you haven't lynched somebody then you can't be called a racist. Somebody has to be able to say that racists are not monsters. They are people with loving families, regular folk who pay taxes. Somebody needs to get the job of deciding who is racist and who isn't. Or maybe it's time to just scrap the word "racist". (Adichie, 2014a, p. 390).

As opressões não caminham sozinhas, são interligadas e podem ser consequências umas das outras. À identidade de raça negra, historicamente, desde a escravidão e o período pós-escravatura, foram negados direitos, educação, bens sociais básicos e oportunidades. Portanto a classe cruza-se com a configuração das raças, à negra é reservada a posição mais baixa na sociedade.

Ainda que negros e brancos pobres sejam minorias sociais enquanto classe, a identidade de raça reserva aos brancos um privilégio que aos negros é negado. Ifemelu novamente aponta um argumento defensivo branco, o humanismo, uma forma de negligenciar as opressões que os negros sofrem devido a sua raça ao colocar em uma identidade que tenta incorporar brancos e negros como iguais o peso de nivelar todos os seres humanos, ainda que os fardos sejam diferentes. $O$ namorado de Ifemelu rebate o frágil e frequente discurso humanista com o argumento de quem o utiliza e dele se beneficia, são os brancos: quem são os que podem optar por não perceber a raça? Aqueles que não são por ela influenciados, silenciados e excluídos, aqueles que são beneficiados por essa categorização que diminui a concorrência ao negar a mesma linha de partida e o mesmo percurso a uma parcela da população, a população negra:

Post do blog: What Academics Mean by White Privileged, or Yes It Sucks To Be Poor and White but Try Being Poor and Non-White [...] The Appalachian hick guy is fucked up, which is not cool, but if he were black, he'd be fucked up plus. He also said to Professor Hunk: Why must we always talk about race anyway? Can't we just be human beings? And Professor Hunk replied - that is exactly what white privilege is, that you can say that. Race doesn't really exist for 


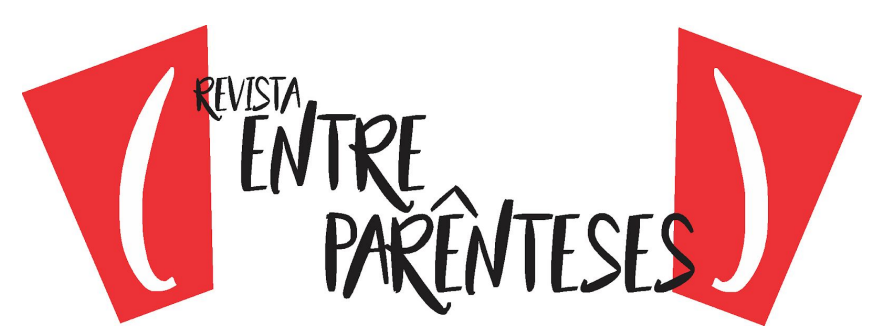

you because it has never been a barrier. Black folks don't have that choice. The black guy on the street in New York doesn't want to think about race, until he tries to hail a cab, and he doesn't want to think about race when he's driving his Mercedes under the speed limit, until a cop pulls him over. So Appalachian hick guy doesn't have a class privilege but he sure as hell has race privilege (Adichie, 2014a, p. 429).

Ainda sobre o privilégio branco, Ifemelu aborda a temática das políticas sociais de reparação histórica dedicadas à população negra devido ao contexto histórico escravocrata e de segregação racial que impossibilitou que os negros tivessem as mesmas oportunidades que os brancos e cujas consequências se estendem até os dias de hoje. A protagonista rebate o argumento da população privilegiada que atribui as conquistas dos negros a essas políticas e desconsidera os privilégios provenientes da sua identidade de raça branca, que sempre mantiveram as regulações das relações de poder hegemônicas em suas mãos. Post do blog: "Understanding America for the Non-American Black: Thoughts on the Special White Friend": "[...] that white people earned their place at jobs and school while black people got it because they were black. But in fact, since the beginning of America, white people have been getting jobs because they are white" (Adichie, 2014a, p. 448).

O romance Americanah contempla uma pluralidade de aspectos ligados às identidades subjugadas experimentadas pela protagonista, em especial a forma como a raça é construída nos Estados Unidos e é percebida na perspectiva de uma negra não-americana, como a protagonista se intitula no blog onde descarrega suas opiniões sobre uma América racista. Ao olhar crítico de Ifemelu não escapam questões como a linguagem, o colorismo, a estética, as relações interraciais, os espaços racialmente marcados, o olhar estrábico que os americanos dão para a raça ao fingirem não a perceber, e, sobretudo, o modo como a sociedade hierarquiza os sujeitos de forma racializada e reserva às mulheres negras a base da pirâmide econômica-social. O olhar de uma "non-american black" incide também sobre a comunidade afro-americana, revelando estratificações e movimentos contraditórios 


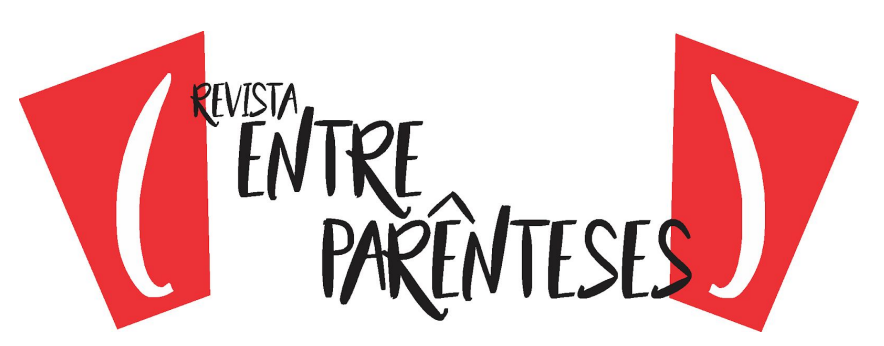

de inclusão e exclusão, pertença e estranhamento entre negros e negras nascidos/as nos EUA e herdeiros da escravatura e da segregação racial, e negros e negras estrangeiras, de imigração recente, muitos deles/as sem possuírem 0 ambicionado green card, o que os coloca à margem do corpo nacional americano.

Os questionamentos da blogueira desacomodam os leitores que permanecem imersos em um mar de verdades absolutas construídas quer com o propósito de regular os corpos das identidades racializadas, no intuito de manter o poder hegemônico nas mãos de identidades brancas-patriarcais-eurocentradas, quer com o propósito de definir resistências e identidades de um modo normativo e, de alguma forma, essencializante.

Imaginários estereotipados são (re)contados e (re)forçados quando as histórias e estórias das identidades subalternizadas são contadas por aqueles que as subjugam, mas a estereotipização também não está ausente nas estratégias de resistência das comunidades oprimidas, que podem assumir, elas próprias, contornos de opressão ou, pelo menos, de exclusão, marginalização ou menorização. A autora nigeriana convida os leitores, através de uma narrativa comprometida politicamente, a conhecer histórias que não correspondem a construtos limitadores dessas identidades e dos espaços que elas ocupam, revelando subjetividades complexas e a forma como atravessam categorias identitárias que sustentam coletivos, desconstruindo-os, e revelando os seus limites e contradições, quer enquanto categorias, quer face às subjetividades, sempre múltiplas e complexas, que mesmo uma perspectiva interseccional não consegue contemplar.

A narrativa de Adichie repele o que Martins (2016a) chama de uma colonialidade das categorias identitárias provenientes do Norte, tendo em consideração as experiências vivenciadas pela protagonista no que concerne a raça, que se tornam realidade a partir da chegada de Ifemelu no contexto americano que carrega um passado escravocrata que ainda pulsa e sufoca os que dele descendem. Ainda que a cor da pele seja comum, a configuração de Ifemelu enquanto imigrante 


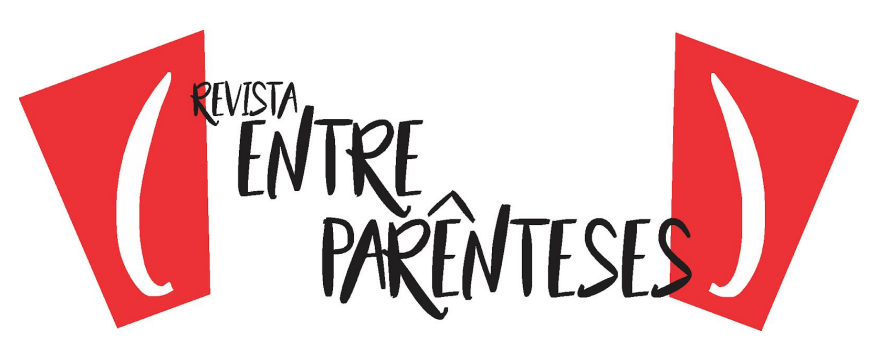

e proveniente da Nigéria, um país que não configura a raça como uma categoria que estratifique a sociedade, configura um grupo social diferente dos afro-americanos.

\section{REFERÊNCIAS}

ADICHIE, Chimamanda Ngozi. Americanah. New York: Anchor Books, 2014a.

Americanah - International Authors' Stage." Youtube, 20 mai. 2014b. Web. Disponível em: <https://www.youtube.com/watch?v=b8r-dP9NqX8> Acesso em 25 abr. 2017

Hair is Political. Youtube. Youtube, 10 abr. 2013a. Web. Disponível em: <https://www.youtube.com/watch?v=4ck2034DS64> Acesso em 25 abr. 2017

2013b. My new novel is about love, race... and hair. Farafina Books, 08 abr.
Web. $<$ https://farafinabooks.wordpress.com/2013/04/08/chimamanda-ngozi-adichie-my-ne w-novel-is-about-love-race-and-hair/> Acesso em 28 mai. 2017

Disponível

The Danger of a Single Story. Farafina Books, 11 abr. 2013c. Web. $<$ https://farafinabooks.wordpress.com/2013/04/11/chimamanda-adichie-the-danger-of -a-single-story/> Acesso em 28 mai. 2017.

FANON, Frantz. Peles Negras Máscaras Brancas. Rio de Janeiro: Fator, 1983.

GILROY, Paul. The Black Atlantic: Modernity and Double Consciousness. Cambridge: Harvard University Press, 1993.

GROSFOGUEL, Ramón. Decolonizing Post-Colonial Studies and Paradigms of Political-Economy: Transmodernity: Journal of Peripheral Cultural Production of the Luso-Hispanic World 1.1 (2011).

HALL, S.; GAY, P. Questions of Cultural Identity. New York: SAGE Publications Ltd., 1996.

HALL, Stuart. Cultural identity and diaspora. In: WILLIAMS, Patrick; CHRISMAN, Laura (eds.). Colonial Discourse and Post-Colonial Theory: a reader. New York: Columbia University Press, 1994.

IGBOANUGO, Ada. We don't do race in nigeria, we do ethnicity... a lot \| chimamanda adichie speaks exclusively to vogue. Ynaija.com, 15 mar. 2015. Web. 


\section{("înum}

Disponível

em: $<$ https://ynaija.com/dont-race-nigeria-ethnicity-lot-not-race-chimamanda/> Acesso em 27 mai. 2017.

Back, Les; SOLOMONS, John. Theories of race and racism: a reader. London: Routledge, 2000.

MAALOUF, Amin. As Identidades Assassinas. Lisboa: Difel, 1999.

MARTINS, Catarina, 0 reverso do moderno nas narrativas migrantes de mulheres africanas contemporâneas, comunicação apresentada no Colóquio "Identidades em movimento: memória (trans)cultural e discursos contemporâneos", Faculdade de Letras da Universidade de Lisboa, 2016 (manuscrito cedido pela autora).

- Mulheres poderosas: gênero, raça, sexualidade, classe, nação e outras categorias nómadas na literatura contemporânea de mulheres africanas. In: COLLING, Leandro (org.). Dissidências Sexuais e de Género. Salvador: Edufba, 2016a: 177-192.

Nós e as Mulheres dos Outros. Feminismos entre o Norte e a África. In: RIBEIRO, António Sousa; RIBEIRO, Margarida Calafate (orgs.). Geometrias da Memória: configurações pós-coloniais. Porto: Afrontamento, 2016b: 251-277.

MBEMBE, Achille. Crítica da Razão Negra. Lisboa: Antígona, 2014.

SPIVAK, Gayatri Chakravorty. Can the Subaltern Speak? In: NELSON, Cary; GROSSBERG, Lawrence (eds.). Marxism and the Interpretation of Culture. Illinois: University of Illinois Press, 1988: 271-313.

SAID, Edward. Orientalismo, O Oriente Como Invenção do Ocidente. Tradução: Rosaura Eichenberg. $1^{a}$ edição, São Paulo: Companhia das Letras, 2007.

MUDIMBE, Valentim Yves. A invenção da África: gnose, filosofia e a ordem do conhecimento. Lisboa: Mangualde: Luanda: Edições Pedago; Edições Mulemba, 2013a.

Americanah. Chimamanda, n.d. Web. Disponível em: <http://chimamanda.com/books/americanah/> Acesso em 20 jun. 2017

Recebido em 30/04/2018

Aceito em 28/09/2018. 